Obere Extremität 2021 $\cdot 16: 130-134$ https://doi.org/10.1007/s11678-021-00624-1 Received: 29 October 2020

Accepted: 12 January 2021

Published online: 5 February 2021

(c) The Author(s) 2021

\author{
Anna-K. Tross ${ }^{1}$ D $\cdot$ Philip-C. Nolte ${ }^{2}$ Markus Loew ${ }^{3} \cdot$ Marc Schnetzke $^{2,3}$. \\ Sven Lichtenberg ${ }^{3}$ \\ ${ }^{1}$ Clinic for Orthopedics and Trauma Surgery, Heidelberg University Hospital, Heidelberg, Germany \\ ${ }^{2}$ Clinic for Trauma and Orthopaedic Surgery, BG Trauma Center Ludwigshafen at the University of \\ Heidelberg, Heidelberg, Germany \\ ${ }^{3}$ DEUTSCHES GELENKZENTRUM HEIDELBERG, ATOS Klinik Heidelberg, Heidelberg, Germany
}

\title{
Surgical reconstruction of the anterolateral acromion with a tricortical iliac crest bone graft after extensive acromioplasty
}

\section{A case report}

\section{Medical history}

A 51-year-old right-hand-dominant female patient presented to our outpatient department with left shoulder impairment. She reported painful shoulder motion and was suffering from occasional night pain, reduced shoulder mobility, and a subjective loss of strength, all of which were not alleviated despite extensive physical therapy. During the previous 7 years she underwent a total of five arthroscopic shoulder surgeries including rotator cuff reconstruction and anterior acromioplasty in another clinic.

\section{Physical examination}

Physical examination of the left shoulder revealed deltoid muscle atrophy and visible as well as palpable muscle gap formation at the lateral deltoid muscle. Active range of motion was reduced when compared with the contralateral shoulder, at $70^{\circ}$ of anterior elevation and abduction and $40^{\circ}$ of external rotation. Passive range of motion was normal and symmetric. The patient was found to have reduced muscular strength in anterior elevation and abduction (4/5) when compared with the contralateral shoulder.

\section{Preoperative planning}

Anteroposterior, axillary, and outletview radiographs of the left shoulder joint demonstrated no signs of osteoarthritis and a well-centered humeral head with three remaining bone anchors in the area of the humeral footprint from prior procedures (• Fig. 1). The preoperative radiographs revealed extensive bone loss of the acromion following previous surgeries (• Fig. 2).

Magnetic resonance imaging (MRI) demonstrated intact subscapularis and infraspinatus muscle tendons. The supraspinatus muscle had a first-grade muscular atrophy according to the classification of Thomazeau without fatty infiltration; however, the tendon itself was found to be intact. Furthermore, a discontinuity between the lateral head of the deltoid muscle and its origin at the anterolateral acromion was visible (- Fig. 3).

\section{Diagnosis}

With respect to the deltoid muscle weakness and palpable muscle gap formation seen during the physical examination and the radiological finding of a narrow and short anterior acromion, we concluded that excessive acromioplasty had caused the functional deltoid muscle insufficiency in this patient's shoulder.

\section{Therapy}

Nonoperative and operative treatment options were thoughtfully discussed with the patient. Despite a relatively good residual left shoulder function, the patient elected to undergo surgery due to severe pain symptoms.

\section{Surgical technique}

The patient was placed in the beach chair position under general and regional (interscalene block) anesthesia. Examination under anesthesia was performed and demonstrated free passive range of motion without instability. The patient's left iliac crest and left shoulder were draped in a sterile fashion. First, a $3.5 \times 2-\mathrm{cm}$ tricortical iliac crest bone graft was harvested via a standard technique.

On open approach along the course of the old scar, anterolateral to the left acromion, was implemented. The acromial part of the deltoid muscle tendon origin was found to be retracted and showed fibrotic degeneration. The deltoid muscle was split at its intersection between the anterior and lateral part. Due to scarring at the humeral head, the rotator cuff was not clearly identifiable; however, 

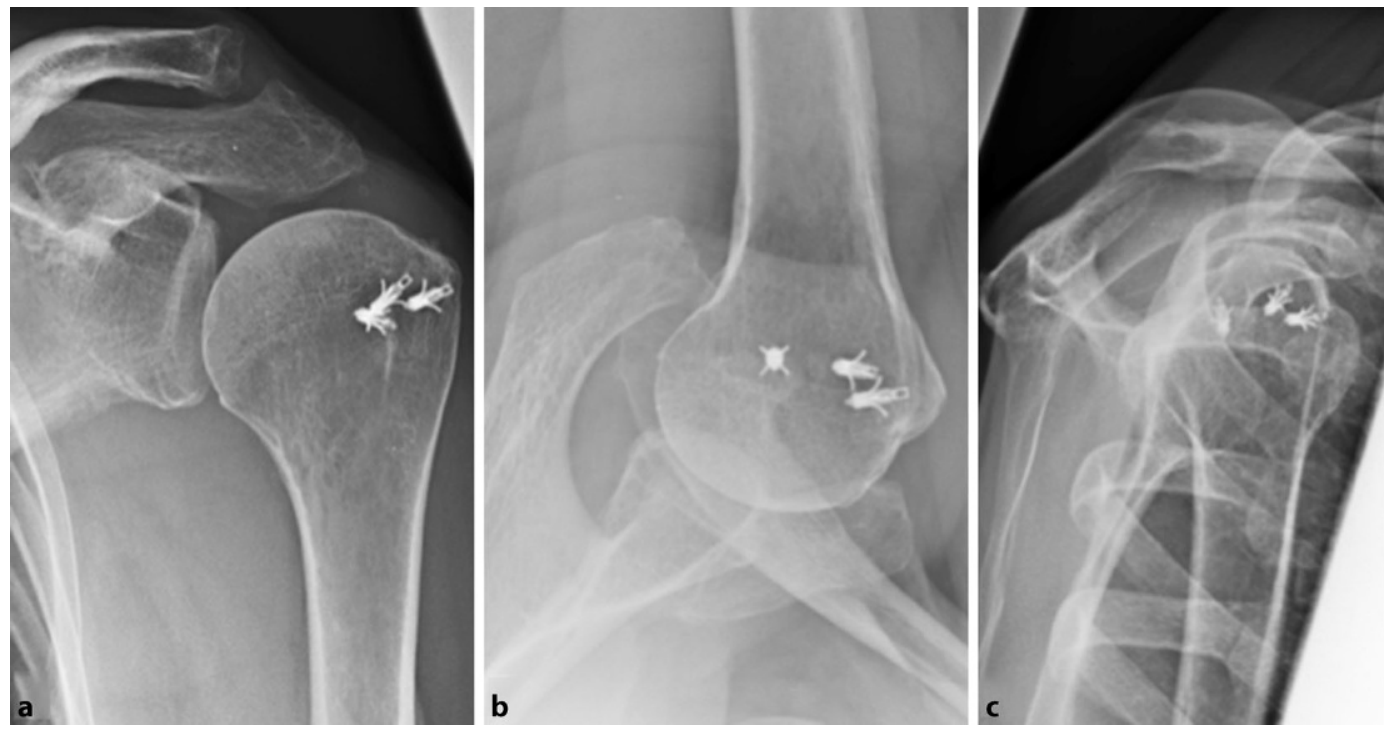

Fig. $1 \varangle$ Preoperative radiographs of the patient's left shoulder. a Anteroposterior, $\mathbf{b}$ axillary, and c outlet-view images. Note the three remaining bone anchors in the proximal humerus after surgical rotator cuff reconstruction in the past

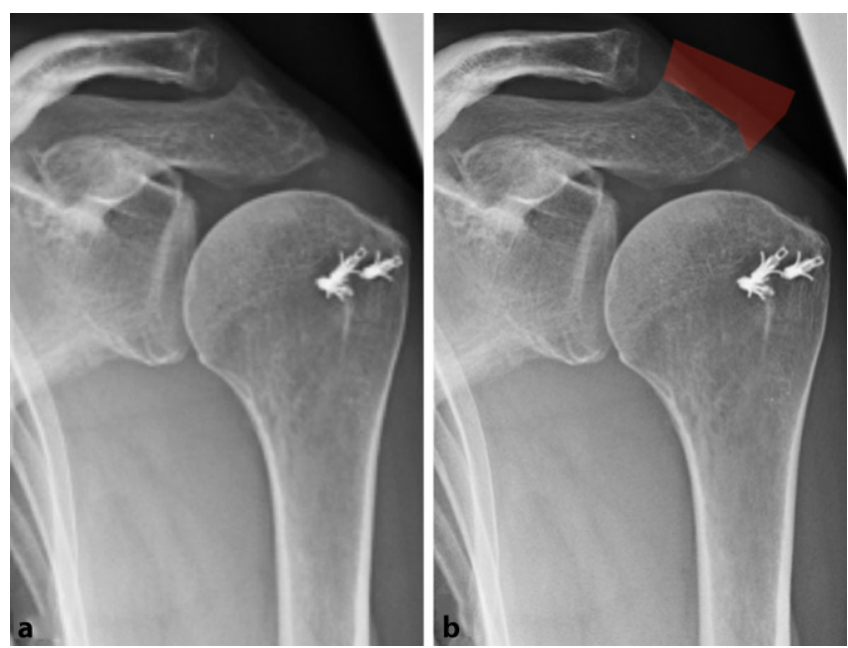

Fig. $2<$ Preoperative radiographs of the patient's left shoulder. a Anteroposterior view and b anteroposterior view with the assumed anterolateral acromion resection shaded in red as the likely cause of shoulder impairment was suspected to be the insufficient deltoid, no extensive dissection at the rotator cufffootprint was performed. The deltoid muscle was then mobilized meticulously while protecting the axillary nerve. The lateral clavicle was visualized, and it was noted that the corresponding articular surface of the acromion was absent.

The remaining anterior acromion was microfractured with an automatic drill to create a bleeding bone bed to facilitate optimal healing of the iliac crest bone graft. The tricortical iliac crest bone graft was cut down to a size of $3 \times 2 \mathrm{~cm}$ and several drill holes were drilled into the future anterior and lateral parts of the bone graft to allow for transosseous suturing of the deltoid. Two Kirschner wires were inserted through the iliac crest bone graft, before it was temporarily fixed to the remaining acromion. The Kirschner wires were then overdrilled and two $3.5-\mathrm{mm} \times 50$ $\mathrm{cm}$ cannulated screws were inserted, resulting in a stable reconstruction of the acromion.

Two 1-mm steel cerclage wires were passed through the cannulated screws. Transosseous no. 2 high-strength sutures (\#2 FiberWire, Arthrex, Naples, FL, USA) were then inserted through the prepared drill holes and through the deltoid muscle tendon. Tension was applied to the sutures and the deltoid muscle was tied to the bone graft. The cerclage wires were twisted and cut to secure the construct. Following copious wound irrigation, a drainage was inserted and layered wound closure was performed.

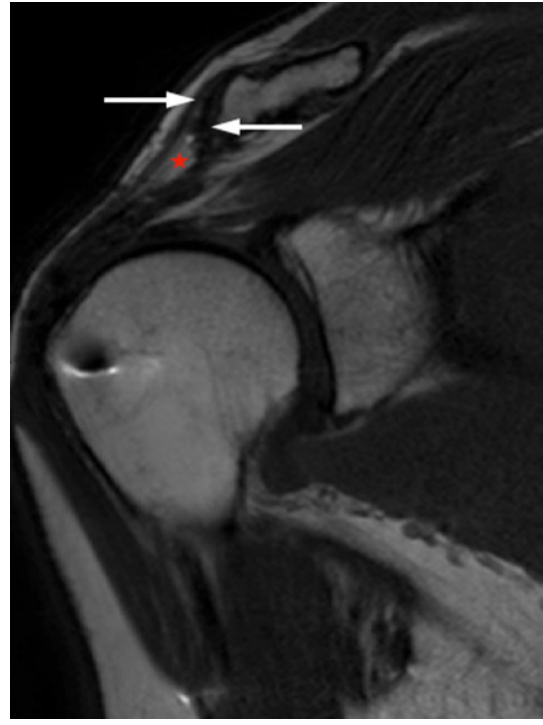

Fig. $3 \Delta$ Preoperative magnetic resonance imaging of a left shoulder (T1-weighted). The deltoid muscle is only partially attached to its origin at the acromion. The supraspinatus muscle tendon volume is reduced but the tendon is still intact and fixed to the tuberosity. White arrows indicate the remaining deltoid muscle fibers. Red asterisk shows the gap between the remaining deltoid muscle fibers

\section{Postoperative treatment}

Postoperatively, the arm was placed in an abduction sling for 6 weeks and passive range of motion was limited to a maximum of $90^{\circ}$ of abduction and anterior elevation. From week seven to 12, gradual active range of motion was allowed. At 3 months postoperatively, the shoulder 
was allowed to be used without restriction.

Immediate postoperative radiographs showed no signs of hardware dislocation and at 3 months postoperatively bony healing of the iliac crest bone graft was demonstrated (see - Figs. 4 and 5). At final follow-up (7.5 months), improved anterior elevation $\left(170^{\circ}\right)$ and abduction $\left(120^{\circ}\right)$ was achieved. External rotation was still reduced $\left(10^{\circ}\right)$ and internal rotation remained constant. Full strength in anterior elevation, abduction, and external rotation of the left shoulder was achieved when compared with the contralateral side. Because of hardware irritation from the steel cerclages, these were removed 8 months postoperatively.

\section{Discussion}

In 1972 Charles Neer pioneered the term "impingement syndrome" as he was convinced that rotator cuff ruptures were caused by a conflict between the rotator cuff tendons and the acromial arch [15]. Later evidence showed that the pathogenesis of rotator cufflesions is multifactorial instead and is influenced by physiological aging processes, vascular changes, and lifestyle [13]. However, following Neer's hypothesis, subacromial decompression to widen the subacromial space became a frequently performed surgical procedure for patients with chronic impingement syndromes that did not respond to a course of nonoperative treatment [20]. Subacromial decompression can be performed open [15] or arthroscopically [4] and typically involves acromioplasty, coracoacromial ligament resection, and bursectomy [6]. Open total acromionectomy was a more radical solution to target chronic tendinitis for the same reason [2, 9] and was popular in the 1970s [10]. An obvious disadvantage of this procedure was the retraction of the deltoid tendon and soft tissue adhesions over time, resulting in poor function and pain [16].

The patient in this case presented with severe pain and functional impairment after multiple shoulder surgeries. On preoperative imaging as well as intraoperatively, we detected a missing part of the anterior acromion suggestive of open acromionectomy or excessive acromioplasty. A scar formation anterolateral to the acromion indicated that an open procedure had been performed. In a review of the literature, we found case reports about complications and complication management following total acromionectomy $[1,5,10]$ as well as reports about complications and complication management after excessive arthroscopic acromioplasty [3, 12, 14, 18].

For acromion reconstruction, we used cannulated screws and steel wire cerclages to perform reduction and internal fixation of an iliac crest tricortical bone autograft to the anterior acromion and sutured the deltoid muscle tendon to the bone graft-a technique that has been described by Forsythe et al. [5]. Another described technique by Agneskirchner et al. [1] was the reconstruction of the coracoacromial arch with an iliac crest bone graft attached to a 10-hole reconstruction plate, which was fixated to the scapular spine and to the coracoid with screws. Jeon et al. [10] harvested a tricortical bone graft with a strip of fascia lata attached to reconstruct the acromion in ten cases after acromionectomy. The graft was secured to the remaining acromion and in cases of severe retraction of the deltoid, the muscle was sutured to the fascia lata instead of to the bone graft directly.

Our patient did clinically well 7 months after acromion reconstruction. However, the literature on clinical outcomes after revision surgery following failed acromioplasty is limited. Jeon et al. [10] reviewed the data of ten patients after acromion reconstruction and deltoid muscle tendon refixation as described above. At the final follow-up (58 months), range of motion had improved and all patients reported pain relief; however, patients with supplementary cuff repair had poor results. Forsythe et al. [5] evaluated the clinical outcomes of four patients after acromion reconstruction and deltoid refixation in a similar surgical technique as the one presented in this case report. Pain and function were improved at followup (50 months); however, one patient required revision deltoidplasty for abductor weakness and one patient who
Obere Extremität 2021 · 16:130-134 https://doi.org/10.1007/s11678-021-00624-1 (c) The Author(s) 2021

A. Tross - P. Nolte - M. Loew - M. Schnetzke · S. Lichtenberg

Surgical reconstruction of the anterolateral acromion with a tricortical iliac crest bone graft after extensive acromioplasty. A case report

\section{Abstract}

Subacromial decompression is one of the most frequently performed procedures in the setting of arthroscopic shoulder surgery and typically includes acromioplasty. However, the indication for acromioplasty remains a subject of debate. Possible complications involve deltoid muscle insufficiency due to an excessive removal of the anterior acromion. This case report is intended to draw attention to this particular complication and its management.

Keywords

Shoulder - Acromionectomy · Deltoid insufficiency - Acromion reconstruction . Arthroscopy

Wiederaufbau des anterolateralen Akromions mittels trikortikalem Beckenkammspan nach ausgedehnter Akromioplastik. Fallbeispiel

\section{Zusammenfassung}

Die subakromiale Dekompression mit typischerweise durchgeführter Akromioplastik ist ein häufig ausgeführter Operationsschritt im Rahmen arthroskopischer Schulteroperationen. Die Indikationsstellung zur Akromioplastik ist bis heute Gegenstand kontroverser Diskussionen. Mögliche Komplikationen sind z. B. eine Insuffizienz des M. deltoideus durch Entfernen von zu großen knöchernen Anteilen des vorderen Akromions. Auf diese spezielle Komplikation sowie auf das Komplikationsmanagement soll durch diesen Fallbericht aufmerksam gemacht werden.

Schlüsselwörter

Schulter - Akromionektomie - DeltaInsuffizienz · Akromionrekonstruktion . Arthroskopie 

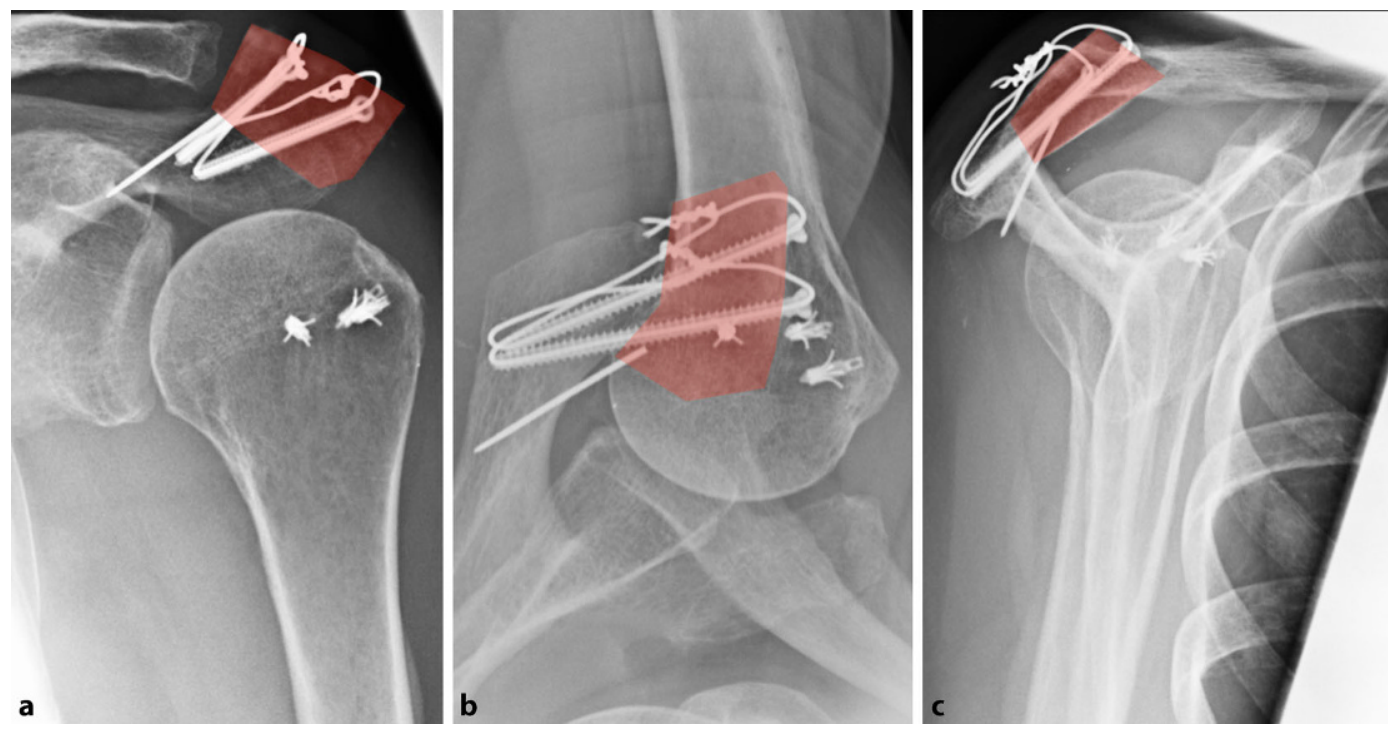

Fig. $4<$ Postoperative (7 weeks) radiographs of the patient's left shoulder. a Anteroposterior, $\mathbf{b}$ axillary, and c outlet-view postoperative radiographs. The acromion was reconstructed with an iliac crest bone graft. Red shaded area, tricortical bone block
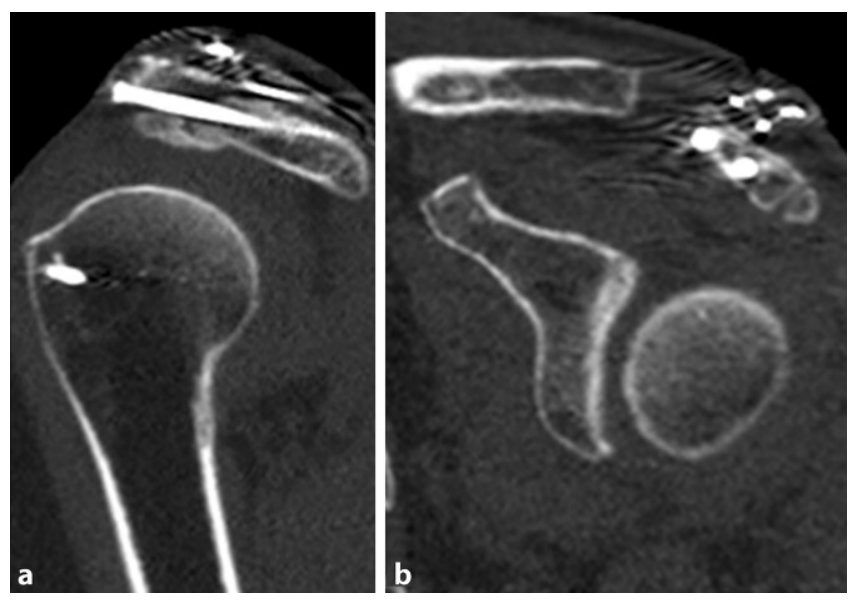

Fig. $5<$ Postoperative (7 months) computed tomography images of the patient's left shoulder. a Coronal and b sagittal view. The iliac crest bone graft is secured to the acromion and fixed by two cannulated screws

underwent concomitant latissimus dorsi transfer had limited functional improvement but decreased pain. Three of four patients required hardware removal just as the patient did in this case report.

As an important message of this case report we would like to raise awareness among surgeons of the possible complications after acromioplasty. First, the indication for acromioplasty must be considered carefully. Appropriate preoperative imaging is essential to recognize other possible reasons for impingement symptoms that may clinically appear as impingement symptoms such as instability and osteoarthritis but will require a different management. Further, preoperative radiographs should include not only anteroposterior and axillary views but also subacromial outlet or y-views to assess the acromial anatomy and possible acromial fractures. It is recommended to perform MRI so as to exclude other potential reasons for impingement symptoms.

Second, arthroscopic acromioplasty should only be performed for chronic impingement symptoms that did not respond to a course of nonoperative treatment [6]. Arthroscopic acromioplasty is considered a rather simple procedure with low complication rates varying between $1 \%$ and $4 \%$ [19]. However, the indication for and benefit of arthroscopic acromioplasty is the subject of debate. Multiple studies have demonstrated that the procedure a) does not provide clinical benefits over placebo in pain, function, or health-related quality of life, and b) the clinical results are not superior to nonoperative treatment with special physiotherapy treatment regimens $[8,11,17]$.

Third, if acromioplasty is performed, over-resection of the anterolateral acromion should be avoided as it may result in acromion fractures $[3,12,14$, 18, 19]. Iatrogenic detachment of the deltoid muscle can occur either directly during electrocautery processes or due to an acromial avulsion fracture [3, 7 , 14] and must be avoided as it results in disastrous clinical impairment [7].

Fourth, to discover the rare complication of an iatrogenic acromion fracture after arthroscopic acromioplasty, postoperative radiographs should include anteroposterior, axillary, and subacromial outlet or $y$-views for the same reason as mentioned before.

\section{Practical conclusion}

- The indication for acromioplasty must be considered carefully.

- Pre- and postoperative radiographs should include not only anteroposterior and axillary views but also subacromial outlet or $y$-views to assess the acromial anatomy and to discover the rare complication of an iatrogenic acromion fracture after acromioplasty.

- In our own practice, bone resection is performed for acromion types II or III according to the Bigliani classification in cases were rotator cuff reconstruction is performed. 
- In our own practice, the inferior part of the coracoacromial ligament and the anterior bone spur are resected in order to create a plane undersurface of the acromion.

- If acromioplasty is performed, over-resection of the anterolateral acromion should be avoided as it may result in acromion fractures. We recommend evaluating the extent of decompression by switching the camera from posterior to anterolateral view.

\section{Corresponding address}

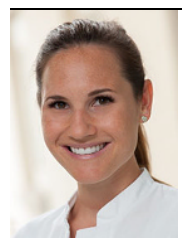

Dr. med. Anna-K. Tross

Clinic for Orthopedics and

Trauma Surgery, Heidelberg University Hospital Schlierbacher Landstr. 200a, 69118 Heidelberg, Germany anna-katharina.tross@ med.uni-heidelberg.de

Funding. Open Access funding enabled and organized by Projekt DEAL.

\section{Compliance with ethical guidelines}

Conflict of interest. A.-K. Tross: The author, her immediate family, and any research foundation with which she is affiliated have not received any financial payments or other benefits from any commercial entity related to the subject of this article. P.-C. Nolte: The position of PCN at the Steadman Philippon Research Institute (08/2019-08/2020) was supported by Arthrex. The author, his immediate family, and any research foundation with which he is affiliated have not received any financial payments or other benefits from any commercial entity related to the subject of this article. M. Schnetzke: The author, his immediate family, and any research foundation with which he is affiliated have not received any financial payments or other benefits from any commercial entity related to the subject of this article. M. Loew: M. Loew is a consultant for and receives royalties from Wright/Tornier Cie. M. Loew receives royalties from Wright/Tornier Inc., which is not related to the subject of this work. No company had any input into the review, data analysis, or manuscript preparation. S. Lichtenberg: The author, his immediate family, and any research foundation with which he is affiliated have not received any financial payments or other benefits from any commercial entity related to the subject of this article. S. Lichtenberg is a paid consultant of and receives royalties from Arthrex Inc. and Arthrex GmbH, S. Lichtenberg is also a paid consultant of Exactech Inc.

All procedures performed in studies involving human participants or on human tissue were in accordance with the ethical standards of the institutional and/or national research committee and with the
1975 Helsinki declaration and its later amendments or comparable ethical standards. Informed consent was obtained from all individual participants included in the study.

Open Access. This article is licensed under a Creative Commons Attribution 4.0 International License, which permits use, sharing, adaptation, distribution and reproduction in any medium or format, as long as you give appropriate credit to the original author(s) and the source, provide a link to the Creative Commons licence, and indicate if changes were made. The image or other third party material in this article are included in the article's Creative Commons licence, unless indicated otherwise in a credit line to the material. If material is not included in the article's Creative Commons licence and your intended use is not permitted by statutory regulation or exceeds the permitted use, you will need to obtain permission directly from the copyright holder. To view a copy of this licence, visit http://creativecommons.org/licenses/by/4.0/.

\section{References}

1. Agneskirchner JD, Fredrich $\mathrm{HH}$, Imhoff $A B$ (2001) Acromion reconstruction after total arthroscopic acromionectomy: salvage procedure using a bone graft. Arthroscopy 17:1-4

2. Armstrong JR (1949) Excision of the acromion in treatment of the supraspinatus syndrome; report of 95 excisions. JBone Joint Surg Br 31b:436-442

3. Bonsell S (2000) Detached deltoid during arthroscopic subacromial decompression. Arthroscopy 16:745-748

4. Ellman H (1987) Arthroscopic subacromial decom pression: analysis of one- to three-year results. Arthroscopy 3:173-181

5. Forsythe B, Lavery KP, Warner JJP (2009) Acromionectomy and deltoid deficiency: a solution. Clin Orthop Relat Res 467:1334-1340

6. Garving C, Jakob S, Bauer I et al (2017) Impingement syndrome of the shoulder. Dtsch Arztebl Int 114:765-776

7. Groh Gl, Simoni M, Rolla P et al (1994) Loss of the deltoid after shoulder operations: an operative disaster. J Shoulder Elbow Surg 3:243-253

8. Haahr JP, Østergaard S, Dalsgaard J et al (2005) Exercises versus arthroscopic decompression in patients with subacromial impingement: a randomised, controlled study in 90 cases with a one year follow up. Ann Rheum Dis 64:760-764

9. Hammond G (1971) Complete acromionectomy in the treatment of chronic tendinitis of the shoulder. A follow-up of ninety operations on eighty-seven patients. JBone Joint Surg Am 53:173-180

10. Jeon IH, Koorevaar R, Neumann L et al (2005) Reconstruction of the deltoid and acromion after failed acromionectomy. Clin Orthop Relat Res. https://doi.org/10.1097/01.blo.0000146535. $77776.5 f$

11. Ketola S, Lehtinen J, Arnala I et al (2009) Does arthroscopic acromioplasty provide any additional value in the treatment of shoulder impingement syndrome?: A two-year randomised controlled trial. J Bone Joint Surg Br 91:1326-1334

12. Liodakis $E$, Kenawey $M$, Petri $M$ et al (2011) Rekonstruktion einer iatrogenen Akromionpseudarthrose. Unfallchirurg 114:532-537

13. Löhr JF, Uhthoff HK (2007) Epidemiology and pathophysiology of rotator cuff tears. Orthopade 36:788-795

14. Matthews LS, Burkhead WZ, Gordon S et al (1994) Acromial fracture: a complication of arthroscopic subacromial decompression. J Shoulder Elbow Surg 3:256-261

15. Neer CS 2nd (1972) Anterior acromioplasty for the chronic impingement syndrome in the shoulder: a preliminary report. J Bone Joint Surg Am $54: 41-50$

16. Neer CS 2nd, Marberry TA (1981) On the disadvantages of radical acromionectomy. JBone Joint Surg Am 63:416-419

17. Paavola M, Malmivaara A, Taimela S et al (2018) Subacromial decompression versus diagnostic arthroscopy for shoulder impingement: randomised, placebo surgery controlled clinical trial. BMJ 362:k2860

18. Rupp S, Seil R, Kohn DM (1998) Surgical reconstruction of a stress fracture of the acromion after arthroscopic subacromial decompression in an elite tennis player. Arthroscopy 14:106-108

19. Rupp S, Seil R, Müller B et al (2000) Komplikationen nach arthroskopischer subakromialer Dekompression (ASD). Arthroskopie 13:246-248

20. Yu E, Cil A, Harmsen WS et al (2010) Arthroscopy and the dramatic increase in frequency of anterior acromioplasty from 1980 to 2005: an epidemiologic study. Arthroscopy 26:S142-S147 